\title{
……
}

\section{RESEARCH AND EDUCATION \\ Wear resistance and abrasiveness of CAD-CAM monolithic materials}

\author{
Francesco Saverio Ludovichetti, DDS, ${ }^{a}$ Flávia Zardo Trindade, DDS, MSc, PhD, ${ }^{b}$ Arie Werner, Ing, \\ Cornelis Johannes Kleverlaan, PhD, ${ }^{d}$ and Renata Garcia Fonseca, DDS, MSc, PhD
}

An improvement in the esthetics of lithium disilicate and yttriastabilized tetragonal zirconia ceramics has led to monolithic restorations, eliminating the problem of fracture and chipping of veneering porcelain. ${ }^{1}$ In addition, the advent of computer-aided design and computer-aided manufacturing (CAD-CAM) technology has enabled restorations to be provided in a single session. ${ }^{2}$ More recently, other esthetic CADCAM monolithic materials with similar indications as lithium disilicate and yttria-stabilized tetragonal zirconia ceramic have been introduced. These include zirconia-reinforced lithium silicate ceramic, polymer-infiltrated ceramic, and nanofilled composite resin.

In the absence of veneering porcelain, these materials are in contact with the antagonist, which can be a natural tooth or

\begin{abstract}
Statement of problem. Computer-aided design and computer-aided manufacturing (CAD-CAM) restorations are in contact with the antagonist tooth, either a natural tooth or a restoration. Therefore, clinicians should be aware of the wear resistance of CAD-CAM materials and the wear behavior of the antagonist.
\end{abstract}

Purpose. The purpose of this in vitro study was to evaluate the wear resistance and abrasiveness of CAD-CAM materials.

Material and methods. In a 2-body wear test, the materials IPS e.max CAD (Ivoclar Vivadent AG), Vita Suprinity (Vita Zahnfabrik), Lava Ultimate (3M ESPE), Vita Enamic (Vita Zahnfabrik), and Lava Plus (3M ESPE) acted as abraders and, together with bovine enamel, also as antagonists. Each antagonist wheel ran against each abrader wheel for 200000 cycles, with a spring force of $15 \mathrm{~N}$, and at a rotational speed of $1 \mathrm{~Hz}$ in distilled water. The wear rate was determined with a surface profilometer. The surfaces were observed with scanning electron microscopy, and their hardness, coefficient of friction, and roughness were evaluated.

Results. Lava Plus and IPS e.max CAD exhibited the highest potential for wear of Lava Ultimate. These 2 materials, together with Vita Suprinity, provided the highest wear of enamel and Vita Enamic. Vita Suprinity and IPS e.max CAD had higher wear than Lava Plus, and the inverse was also true. Vita Enamic and Lava Ultimate were among the materials that caused the lowest wear of enamel and all other evaluated materials. Scanning electron microscopy images revealed that except for Lava Ultimate, all other materials damaged enamel, in which Vita Suprinity and IPS e.max CAD were more aggressive when sliding against the materials. Lava Plus had the greatest hardness, followed by Vita Suprinity and IPS e.max CAD, Vita Enamic, and then Lava Ultimate. The coefficient of friction varied from 0.42 to 0.53 . The Vita Enamic and Lava Ultimate showed the highest surface roughness.

Conclusions. The nanofilled composite resin and polymer-infiltrated ceramic were more antagonist-friendly (whether enamel or CAD-CAM material) than glass-ceramics and zirconia. Care should be taken when selecting the material that will contact mainly with glass-ceramics. Hardness should also be considered when selecting a material. (J Prosthet Dent 2018;120:318.e1-e8)

Funding: This work was supported by the São Paulo Research Foundation (FAPESP) (grant: 2014/15637-7).

aPostgraduate student, Department of Dental Materials and Prosthodontics, School of Dentistry, São Paulo State University (UNESP), Araraquara, Brazil.

${ }^{b}$ Postdoctoral student, Department of Dental Materials and Prosthodontics, School of Dentistry, São Paulo State University (UNESP), Araraquara, Brazil.

cEngineer, Department of Dental Materials Science, Academic Centre for Dentistry Amsterdam (ACTA), University of Amsterdam; and Vrije University Amsterdam, Amsterdam, The Netherlands.

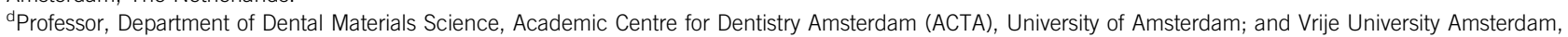
Amsterdam, The Netherlands.

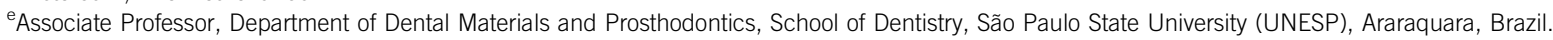




\section{Clinical Implications}

Nanofilled composite resin and polymer-infiltrated ceramics are antagonist-friendly materials, whereas glass-ceramics promote high wear rates on the antagonist enamel and materials. Hardness should be considered when selecting CAD-CAM monolithic materials. The roughness and coefficient of friction of some materials may change during the wear process.

a restoration. Therefore, the wear resistance and abrasiveness of these materials is important. The wear properties of zirconia, ${ }^{3-8}$ lithium disilicate, ${ }^{3,4,6,9,10,11}$ zirconia-reinforced lithium silicate, ${ }^{10}$ polymer-infiltrated ceramic, and nanofilled composite resin ${ }^{6,10,12}$ when opposed to enamel have been reported. However, the multifactorial nature of wear ${ }^{6,13,14}$ makes it important to understand the wear potential of the materials based on the composition and microstructural aspects ${ }^{15-17}$ that will determine their properties. ${ }^{18-24}$ The role that the roughness, ${ }^{6-9,25}$ coefficient of friction, ${ }^{4,14}$ elastic modulus, ${ }^{10}$ and hardness ${ }^{6,14,15}$ play in determining wear potential has been investigated.

However, these studies used enamel as an antagonist, $4,5,7-13,15,26$ and studies exploring the different possibilities of combinations among these materials are lacking. Therefore, the purpose of the present study was to evaluate the wear provided by 5 CAD-CAM monolithic materials on bovine enamel and on each other. To better understand the material behavior, the surface roughness, hardness, and coefficient of friction of the materials were also investigated. The null hypothesis was that no difference would be found among the materials regarding their potential to wear the enamel or each other.

\section{MATERIAL AND METHODS}

The materials used in the present study and their composition are listed in Table 1. Disk-shaped specimens were prepared from each material. The CAD-CAM blocks were shaped into cylinders by using a mechanical turner, cut into disks using a precision saw (IsoMet 1000; Buehler), and then polished with silicon carbide abrasive papers (400-, 600-, 1200-grit papers; 3M) in a polisher (Metaserv 2000; Buehler) under water irrigation. Vita Suprinity (Vita Zahnfabrik) and IPS e.max CAD (Ivoclar Vivadent AG) disks were crystallized (Programat P310; Ivoclar Vivadent AG). Lava Plus (3M ESPE) disks were cut 20\% thicker and then sintered (inFire HTC speed; Dentsply Sirona). Crystallization and sintering were performed by following the manufacturers' recommendations.
For the microhardness test ( $\mathrm{n}=5), 5$ indentations were made in each specimen using a Vickers diamond indenter under 20-N load and a 20-second dwell time. Hardness values (GPa) were calculated according to the equation $\mathrm{H}=\mathrm{P} / 2 \mathrm{~d}^{2}$, where $\mathrm{P}$ is the load in newtons and $\mathrm{d}$ is the average of the diagonal values.

The coefficient of friction $(n=5)$ was measured using a ball-on-flat tribometer (UMT-2; CETR Corp) according to ASTM G133-05 Standard. ${ }^{27}$ Each specimen was secured on a holder, and a load of $5 \mathrm{~N}$ was applied with a 2-mmdiameter stainless steel sphere. A tangential, cyclic 9.7-mm back and forward motion was applied to the specimen at $5 \mathrm{~Hz}$ for 600 seconds without irrigation. A new stainless steel ball was used for each specimen. Testing was conducted at room temperature and humidity.

Surface roughness $(\mu \mathrm{m})(\mathrm{n}=8)$ was analyzed using a confocal microscope (LEXT OLS4100; Olympus). Three equidistant parallel measurements were made on each specimen. The average reading was designated as the $\mathrm{Rq}$ (root mean square roughness) value of each specimen. A single calibrated operator (F.S.L.) recorded all measurements.

The 2-body wear test was performed using the Academic Centre for Dentistry Amsterdam (ACTA) wear machine profiles. ${ }^{28,29}$ One wheel (of 21-mm diameter and $7.5-\mathrm{mm}$ width) containing a $2-\mathrm{mm}$ inner hole (abrader wheel) from each material was prepared (Fig. 1). After gluing 4 CAD-CAM blocks of each material together, a round diamond tip with an inner diameter of $21 \mathrm{~mm}$ was mounted on a table drill and used to obtain the abrader wheels under constant water irrigation. An inner hole of $2 \mathrm{~mm}$ was obtained following the same procedure. The round tip used for the Lava Plus had an inner diameter of $26 \mathrm{~mm}$ to compensate for zirconia shrinkage. Then, the IPS e.max CAD and Vita Suprinity were crystallized, and the Lava Plus was sintered. Each wheel was then mounted on the ACTA wear machine and polished against sequential abrasive wheels to obtain an even and curved cylindrical outer surface shape. A final polish of the outer surfaces was given using P1000 silicon carbide abrasive paper mounted on a wheel. Two antagonist metal wheels (of 48-mm diameter and 10-mm thickness) with 10 rectangular compartments (of 14-mm length, 10-mm width, and a maximum of 3-mm thickness) were used. Rectangular specimens (3 from each material, 4 from bovine enamel, and 1 from Z250 composite resin) were bonded using Panavia F2.0 (Kuraray Dental) to the antagonist wheel compartments of the ACTA wear machine (Fig. 2). Each specimen wheel was polished following the same protocol used for the abrader wheel. Finally, each abrader wheel rotated against each antagonist wheel.

Each antagonist wheel ran for 200000 cycles with a spring force of $15 \mathrm{~N}$ at a rotational speed of $1 \mathrm{~Hz}$ in distilled water at room temperature. Then, 10 tracings were made 
Table 1. Materials used in study

\begin{tabular}{lll}
\hline Material & \multicolumn{1}{c}{ Classification } & \multicolumn{1}{c}{ Composition } \\
\hline Lava Ultimate & Resin nanoceramic & $80 \%$ nanoceramic and 20\% resin matrix \\
\hline Vita Enamic & Polymer-infiltrated ceramic network & $86 \%$ feldspathic ceramic and $14 \%$ polymer \\
\hline Vita Suprinity & Zirconia-reinforced & Lithium silicate with $\sim 10 \%$ ZrO \\
& lithium silicate ceramic & \\
\hline IPS e.max CAD & Lithium disilicate ceramic & $57 \%-80 \% \mathrm{SiO}_{2}, 11 \%-19 \% \mathrm{Li}_{2} \mathrm{O}$, \\
& & $0 \%-13 \% \mathrm{~K}_{2} \mathrm{O}, 0 \%-11 \% \mathrm{P}_{2} \mathrm{O}_{5}, 0 \%-8 \% \mathrm{ZrO}_{2}$, \\
& & $0 \%-8 \% \mathrm{ZnO}_{0} 0 \%-5 \% \mathrm{Al}_{2} \mathrm{O}_{3}, 0 \%-5 \% \mathrm{MgO}^{2}$ \\
\hline Lava Plus & Tetragonal polycrystalline zirconia & Vahnfabrik \\
& partially stabilized with 3mol- $\%$ yttria & $99 \% \mathrm{ZrO}_{2}$ \\
\hline
\end{tabular}

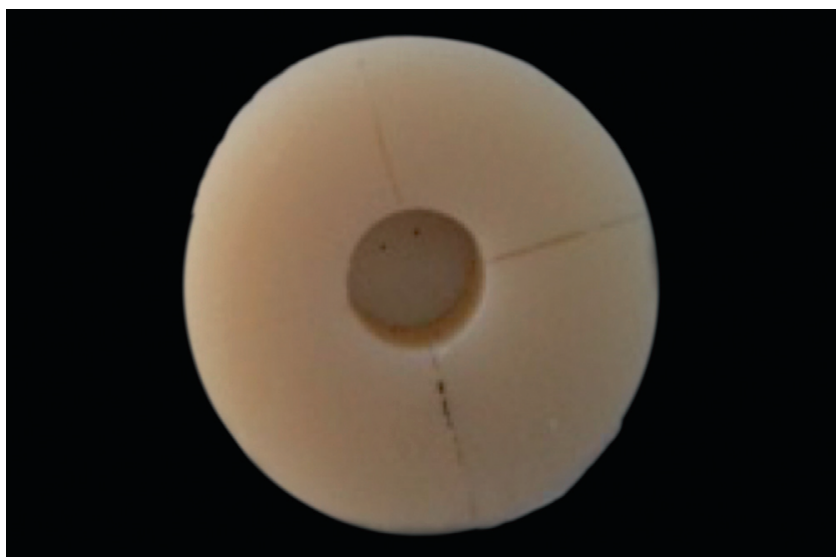

Figure 1. Abrader wheel from Vita Enamic before polishing.

at fixed positions on the worn surface of the specimens using a surface profilometer (PRK profilometer no. 20702; Perthen $\mathrm{GmbH}$ ) to determine the loss of material in $\mu \mathrm{m}$. The average wear rate was calculated from these profiles. ${ }^{28,29}$ The worn surfaces were observed by scanning electron microscopy at $\times 100, \times 500, \times 1000, \times 2000, \times 5000$, and $\times 10000$ (LS15; Zeiss). Scanning electron microscopy (SEM) specimens were made indirectly from epoxy resin (Araldite; Ciba-Geigy) poured into a polyvinyl siloxane impression and gold sputtered for electron conductivity.

The hardness and roughness data were square root transformed before the statistical analysis. Because the assumptions of the analysis of variance were satisfied (Shapiro-Wilk and Levene tests, $P>.05$ ), the hardness, coefficient of friction, and roughness data were submitted to 1-way ANOVA test, followed by the Tukey post hoc test $(\alpha=.05)$ to determine significant differences among the materials. The wear data were analyzed by 2-way ANOVA (abrader and antagonist), followed by the Tukey post hoc test. A statistical analysis was performed using a statistical software program (IBM SPSS Statistics v22.0; IBM Corp).

\section{RESULTS}

Table 2 shows the Vickers hardness mean values, standard deviations, and the statistical results ( $\mathrm{F}=1898.12$;

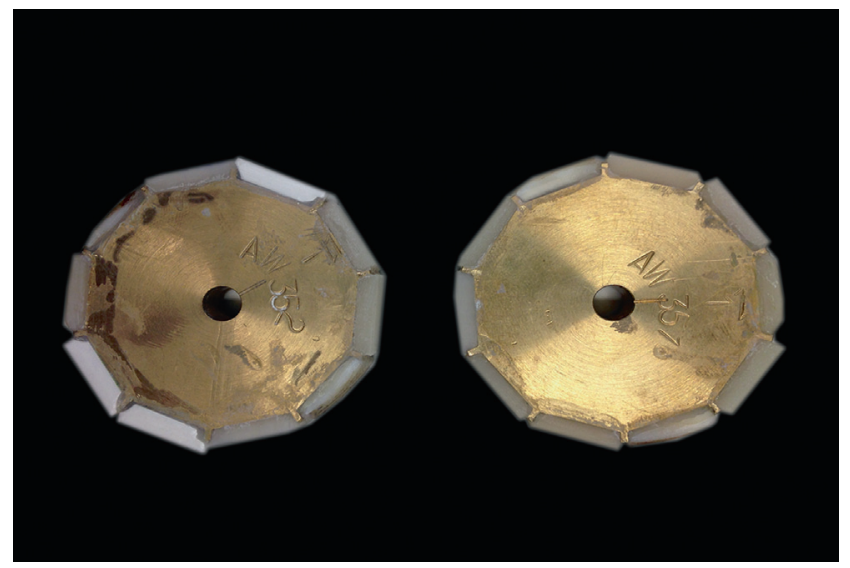

Figure 2. Antagonist wheels before polishing.

$P<.001)$. The hardness result was Lava Plus $>$ (Vita Suprinity=PS e.max CAD) $>$ Vita Enamic (Vita Zahnfabrik) $>$ Lava Ultimate (3M ESPE). Table 3 presents the coefficient of friction mean values, standard deviations, and statistical results $(\mathrm{F}=6.126 ; P<.01)$. Lava Ultimate exhibited a higher coefficient of friction than IPS e.max $\mathrm{CAD}$ and Lava Plus. Roughness mean values (Rq), standard deviations, and statistical results $(\mathrm{F}=167.88$; $P<.001)$ are shown in Table 4. Vita Enamic and Lava Ultimate showed the highest roughness values, whereas the IPS e.max CAD and Vita Suprinity exhibited the lowest mean value. The 2-way ANOVA indicated that the abrader $(\mathrm{F}=31.37 ; P<.001)$ and antagonist $(\mathrm{F}=114.66$; $P<.001)$ factors and their interaction $(\mathrm{F}=29.62 ; P<.001)$ were significant. Table 5 presents the antagonist wear provided by the abrader materials. The IPS e.max CAD, Lava Plus, and Vita Suprinity materials provided higher wear of enamel than the Lava Ultimate and Vita Enamic. Lava Plus and the IPS e.max CAD showed significantly higher potential to wear than the Lava Ultimate. The wear of the Vita Enamic against different materials exhibited the same behavior as the enamel. Vita Suprinity and IPS e.max CAD exhibited the highest wear against the Lava Plus and the lowest against Vita Enamic and Lava Ultimate. IPS e.max CAD and Vita Suprinity exhibited the highest potential to wear against the Lava Plus. 
Table 2. Mean Vickers hardness $(\mathrm{VH}), \pm \mathrm{SD}$, and statistical results

\begin{tabular}{lcl}
\hline Material & Mean & Statistical Results \\
\hline Lava Ultimate & $96 \pm 6$ & A \\
\hline Vita Enamic & $200 \pm 5$ & B \\
\hline Vita Suprinity & $632 \pm 17$ & C \\
\hline IPS e.max CAD & $617 \pm 44$ & C \\
\hline Lava Plus & $1343 \pm 47$ & D \\
\hline
\end{tabular}

SD, standard deviation. Different uppercase letters indicate significant differences $(P<.05)$.

The SEM images of the enamel surface worn by the materials (Fig. 3) revealed deep parallel grooves with broken fragments of Vita Suprinity (Fig. 3C) and a deeply pitted surface when sliding against the IPS e.max CAD (Fig. 3B). Sliding grooves were created by the Lava Plus (Fig. 3E). Slight cracks were caused by Vita Enamic (Fig. 3D), whereas an essentially smooth surface was detected when the enamel was rubbed against the Lava Ultimate (Fig. 3A). SEM images of the surface of the materials against themselves are presented in Figure 4. Lava Ultimate did not modify the surface of the materials, but some of its fragments can be seen on the surface of the Vita Suprinity (Fig. 4A) and IPS e.max CAD (Fig. 4B). Vita Enamic created superficial grooves on the Lava Ultimate (Fig. 4C). Vita Suprinity produced some pits on the Lava Ultimate (Fig. 4D) and Vita Enamic (Fig. 4E), whereas the surfaces of the other materials were flat with some fragments of Vita Suprinity on the IPS e.max CAD (Fig. 4F). Pits created by the IPS e.max CAD can be found on the Vita Enamic (Fig. 4G) and Vita Suprinity (Fig. 4H), whereas smooth flat surfaces were observed for the IPS e.max CAD itself and the Lava Plus. Finally, flat surfaces of Lava Ultimate, Vita Enamic, and Vita Suprinity were created when sliding against the Lava Plus. Some SEM images were lost because of technical problems, and therefore, some of them were repeated at a different magnification.

\section{DISCUSSION}

In the present study, the 2-body wear produced by CAD-CAM monolithic materials on bovine enamel and on themselves ${ }^{28,29}$ was evaluated. The null hypothesis that no difference would be found among the materials regarding their potential to wear the enamel and themselves was rejected. The enamel wear provided by all the tested materials after simulation of 200000 cycles was lower than the clinical 2- and 3-body wear determined in vivo by Lambrechts et $\mathrm{al}^{26}$ after 1 year. Nevertheless, ranking the restorative materials based on their potential to wear enamel is important, especially in patients with high occlusal force and/or bruxism.

In general, Lava Plus and IPS e.max CAD wore the antagonists more than Vita Enamic and Lava Ultimate did, and no significant difference was found in wear potential, either between IPS e.max CAD and Suprinity
Table 3. Mean coefficient of friction, $\pm S D$, and statistical results

\begin{tabular}{lll}
\hline Material & Mean & Statistical Results \\
\hline Lava Ultimate & $0.53 \pm 0.05$ & $\mathrm{~A}$ \\
\hline Vita Enamic & $0.50 \pm 0.04$ & $\mathrm{ABC}$ \\
\hline Vita Suprinity & $0.51 \pm 0.05$ & $\mathrm{AB}$ \\
\hline IPS e.max CAD & $0.45 \pm 0.04$ & $\mathrm{BC}$ \\
\hline Lava Plus & $0.42 \pm 0.02$ & $\mathrm{C}$ \\
\hline
\end{tabular}

SD, standard deviation. Different uppercase letters indicate significant differences $(P<.05)$.

Table 4. Mean roughness (Rq) $(\mu \mathrm{m})$ of polished surfaces, $\pm S D$, and statistical results

\begin{tabular}{lll}
\hline Material & Mean & Statistical Results \\
\hline Lava Ultimate & $0.37 \pm 0.09$ & A \\
\hline Vita Enamic & $0.40 \pm 0.06$ & A \\
\hline Vita Suprinity & $0.05 \pm 0.01$ & C \\
\hline IPS e.max CAD & $0.05 \pm 0.01$ & C \\
\hline Lava Plus & $0.29 \pm 0.04$ & B \\
\hline
\end{tabular}

SD, standard deviation. Different uppercase letters indicate significant differences $(P<.05)$.

(except for Lava Ultimate antagonist) or between Vita Enamic and Lava Ultimate. Other studies also reported that the IPS e.max CAD showed significantly higher enamel wear than the Vita Enamic ${ }^{10}$ and Lava Ultimate. ${ }^{6,10}$ In these studies, as in the present, the IPS e.max CAD showed significantly higher hardness than the Vita Enamic and Lava Ultimate. In addition to the IPS e.max CAD, Lava Plus also exhibited significantly higher hardness than Vita Enamic and Lava Ultimate. Differently from other studies ${ }^{14-16}$ that did not find a strong relationship between hardness and wear potential, Mormann et $\mathrm{al}^{6}$ reported that the lower the hardness, the lower the enamel wear, which is in accordance with the present study. We also observed that the lower the hardness, the lower the antagonist materials' wear. Considering the hardness of the enamel reported by Chun et $\mathrm{al}^{18}(274.8 \mathrm{VH})$ and that found in the present study for the Lava Ultimate, Vita Enamic, IPS e.max CAD, Vita Suprinity, and Lava Plus, we observed that the materials with higher hardness than that of enamel presented higher enamel wear than those with lower hardness. In contrast with our result for the Lava Plus, Mormann et $\mathrm{al}^{6}$ found that the inCoris (Dentsply Sirona), despite its high hardness value, provided the lowest enamel wear rate among the evaluated materials. Possibly, this is related to differences in grain size, composition, or manufacturing process. According to Seghi et $\mathrm{al}_{1}{ }^{15}$ an understanding of the materials' microstructure might be useful in predicting their wear potential.

Besides hardness, other properties may be useful in determining the wear potential of the materials. Wang et $\mathrm{al}^{4}$ reported that when the mismatch of the elastic modulus and the strength between the enamel and 
Table 5. Mean antagonist wear $(\mu \mathrm{m}), \pm \mathrm{SD}$, and statistical results

\begin{tabular}{lcccccc}
\hline & \multicolumn{5}{c}{ Antagonist } \\
\cline { 2 - 7 } Abrader & Enamel & Lava Ultimate & Vita Enamic & Vita Suprinity & IPS e.max CAD & Lava Plus \\
\hline Lava Ultimate & $1.8 \pm 1.0 \mathrm{Ba}$ & $1.2 \pm 1.1 \mathrm{Bab}$ & $0.2 \pm 1.0 \mathrm{Bbc}$ & $0.7 \pm 0.4 \mathrm{Cab}$ & $-0.1 \pm 0.5 \mathrm{Cc}$ & $-0.2 \pm 0.3 \mathrm{Bc}$ \\
\hline Vita Enamic & $0.9 \pm 1.9 \mathrm{Bab}$ & $2.2 \pm 2.4 \mathrm{Ba}$ & $0.5 \pm 0.6 \mathrm{Bab}$ & $0.6 \pm 1.2 \mathrm{Cab}$ & $0.5 \pm 1.4 \mathrm{Cab}$ & $-0.1 \pm 0.5 \mathrm{Bb}$ \\
\hline Vita Suprinity & $3.8 \pm 4.0 \mathrm{Aa}$ & $1.8 \pm 1.6 \mathrm{Ba}$ & $4.3 \pm 5.3 \mathrm{Aa}$ & $2.4 \pm 3.3 \mathrm{Ba}$ & $2.9 \pm 3.5 \mathrm{Ba}$ & $0.1 \pm 0.6 \mathrm{ABa}$ \\
\hline IPS e.max CAD & $6.0 \pm 7.3 \mathrm{Aa}$ & $4.0 \pm 2.6 \mathrm{Aa}$ & $4.0 \pm 4.6 \mathrm{Aa}$ & $3.2 \pm 3.9 \mathrm{Ba}$ & $2.3 \pm 2.8 \mathrm{Ba}$ & $0.4 \pm 0.6 \mathrm{Aa}$ \\
\hline Lava Plus & $5.4 \pm 1.9 \mathrm{Ac}$ & $4.2 \pm 2.6 \mathrm{Ac}$ & $6.5 \pm 3.4 \mathrm{Abc}$ & $14.5 \pm 5.5 \mathrm{Aa}$ & $13.8 \pm 5.6 \mathrm{Aab}$ & $0.0 \pm 0.3 \mathrm{Bd}$ \\
\hline
\end{tabular}

SD, standard deviation. Different uppercase letters indicate significant differences in columns $(P<.05)$. Different lowercase letters indicate significant differences in rows $(P<.05)$.
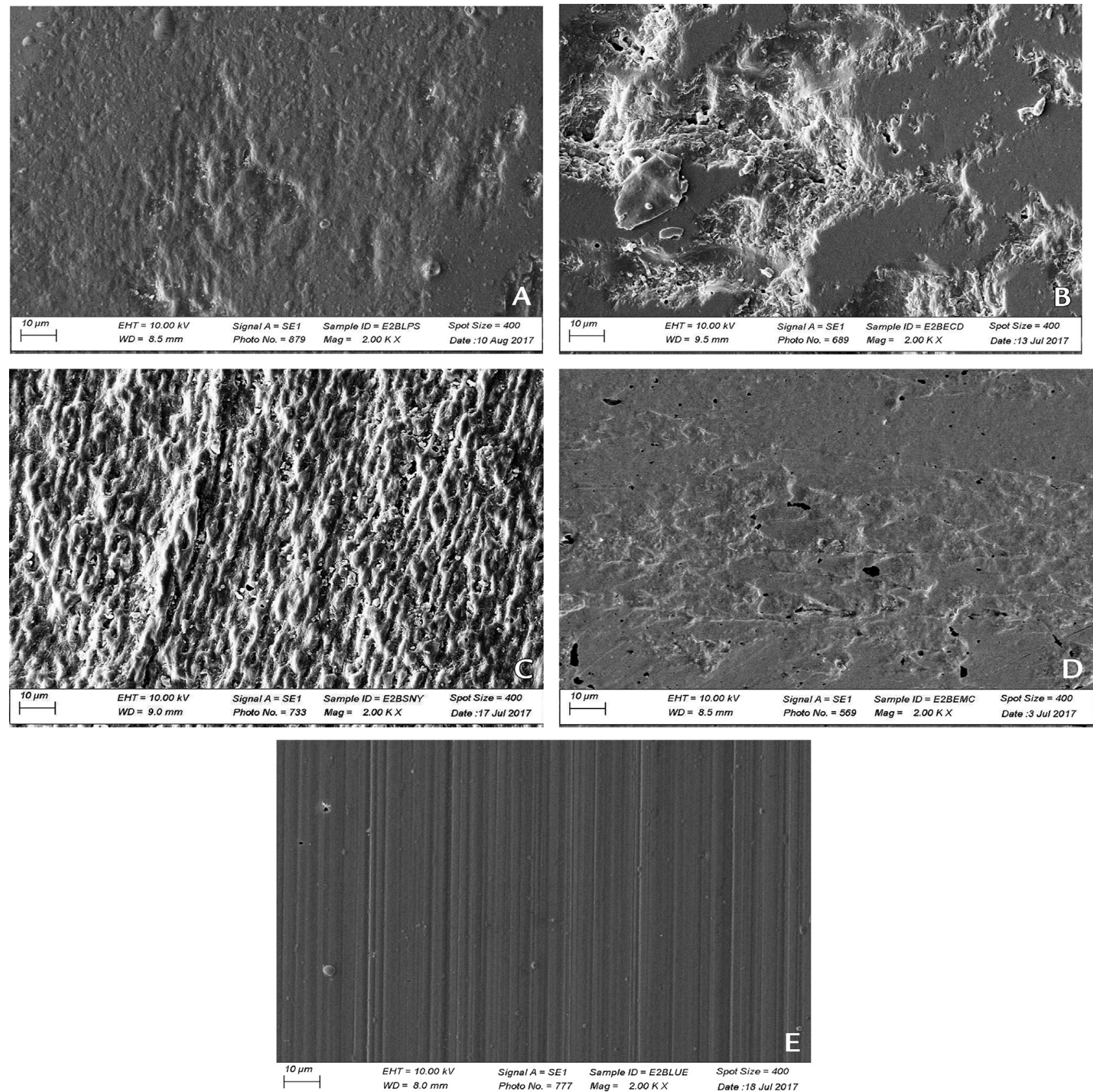

Figure 3. Scanning electron microscope images (original magnification $\times 2000$ ) of enamel surfaces. A, Against Lava Ultimate. B, Against Vita Enamic. C, Against Vita Suprinity. D, Against IPS e.max CAD. E, Against Lava Plus. 

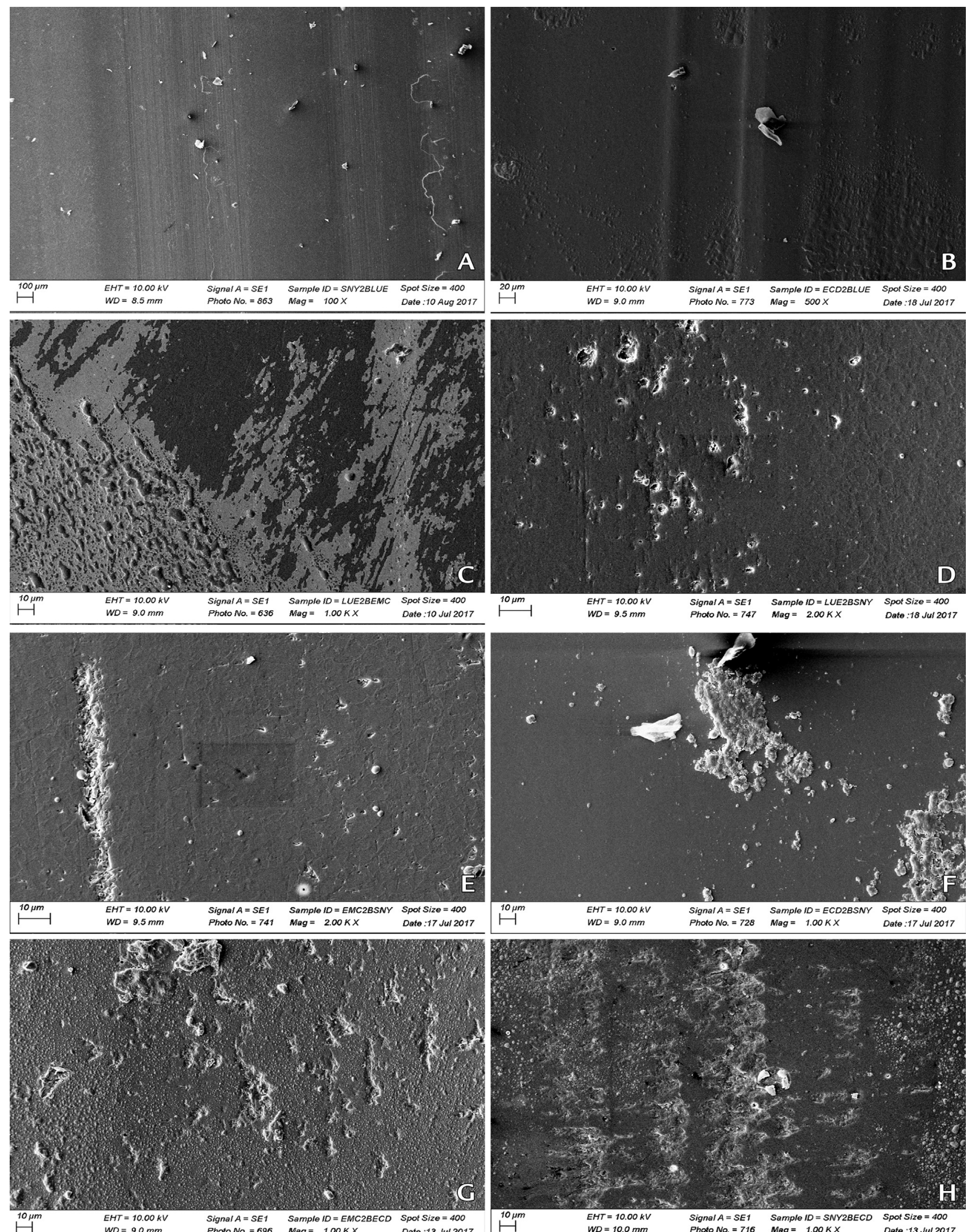

Figure 4. Scanning electron microscope images. A, Vita Suprinity surface against Lava Ultimate (original magnification $\times 100$ ). B, IPS e.max CAD surface against Lava Ultimate (original magnification $\times 500$ ). C, Lava Ultimate surface against Vita Enamic (original magnification $\times 1000$ ). D, Lava Ultimate surface against Vita Suprinity (original magnification $\times 2000$ ). E, Vita Enamic against Vita Suprinity (original magnification $\times 2000$ ). F, IPS e.max CAD against Vita Suprinity (original magnification $\times 2000$ ). G, Vita Enamic against IPS e.max CAD (original magnification $\times 1000$ ). $H$, Vita Suprinity against IPS e.max CAD (original magnification $\times 1000$ ). 
restorative materials are large, the enamel suffers high stress concentration and, consequently, stress abrasion. They stated ${ }^{4}$ that the high strength and toughness of zirconia enabled it to resist surface damage under stress, keeping its fineness and coefficient of friction unchanged over time. In contrast, enamel suffers fatigue wear with microcrack formation and propagation in the subsurface. ${ }^{4,5}$ Therefore, high hardness combined with high flexural strength $(1200 \mathrm{MPa})$ and elastic modulus (210 GPa) may explain the considerable wear potential of the Lava Plus. In addition, as the specimens were exposed to water during the entire experiment, the low temperature degradation of zirconia with an increase in surface roughness ${ }^{19-21}$ might have contributed to the high abrasion of the antagonists. In contrast, the elastic modulus of the IPS e.max CAD $\left(67.2 \mathrm{GPa}^{10}\right.$ and $95 \mathrm{GPa}$ according to the manufacturer) was similar to that of enamel (60 to $100 \mathrm{GPa}^{22}$ ).

Despite the differences in the composition and microstructure ${ }^{17}$ of the lithium disilicate (IPS e.max CAD) and the zirconia-reinforced lithium silicate (Vita Suprinity) materials, they were not statistically different concerning the properties evaluated. In addition, Belli et $\mathrm{al}^{17}$ reported that the Young modulus of these materials was similar. These similar properties explain the similarity in wear behavior found for IPS e.max CAD and Vita Suprinity.

Vita Enamic and Lava Ultimate showed the 2 lowest hardness values among all materials, whereas in the study by Mormann et $\mathrm{al}_{1}{ }^{6}$ the hardness of the Vita Enamic was not significantly higher than that of the Lava Ultimate. In addition, the elastic modulus of $21.5 \mathrm{GPa}$ and 16.0 GPa found for the Vita Enamic and Lava Ultimate, respectively, ${ }^{10}$ is close to that of human dentin (20 GPa ${ }^{23}$ as has been reported by Awada and Nathanson. ${ }^{24}$ The low stiffness and hardness explain the lower potential of the Vita Enamic and Lava Ultimate to wear enamel and other materials. Lawson et $\mathrm{al}^{10}$ observed that IPS e.max CAD and the zirconia-reinforced lithium silicate material, Celtra Duo, with a similar microstructure to that of Vita Suprinity, ${ }^{17}$ were generally stronger, stiffer, and harder than Vita Enamic and Lava Ultimate. The similarity in wear potential observed in the present study was also reported by Mormann et $\mathrm{al}^{6}$ stating that the hybrid ceramic behaved similarly to composite resins concerning enamel wear.

A relationship was not found between roughness, coefficient of friction, and wear behavior. Lava Plus and IPS e.max CAD exhibited significantly higher wear potential but lower roughness than Vita Enamic and Lava Ultimate and a lower coefficient of friction than the Lava Ultimate. Mormann et $\mathrm{al}^{6}$ reported that the IPS e.max CAD showed the lowest roughness value among all the evaluated materials (including Lava Ultimate, Vita Enamic, and inCoris) and significantly higher wear potential than the Lava Ultimate and inCoris. In contrast with some authors ${ }^{7,25}$ who concluded that surface roughness influences and may predict enamel wear, the lack of a relationship found in the present study between surface roughness and wear potential is consistent with other studies. ${ }^{8,9}$ During cyclic sliding, some materials may undergo changes in surface topography, which might modify their abrasiveness. ${ }^{13,15}$ IPS e.max CAD contains approximately $70 \%$ lithium disilicate crystals in a glassy matrix. Wang et $\mathrm{al}^{4}$ reported that during wear against enamel, the lower strength and softer glass matrix of the lithium disilicate glass-ceramic wears more easily than the stronger and harder crystals, increasing the surface roughness and the coefficient of friction of the material. In addition, Culhaoglu and Park ${ }^{11}$ assumed that after the lithium disilicate loses the glaze, an increased rate of particle fracture occurs. The presence of material debris between the rubbing surfaces might increase the friction and accordingly the wear rate, both from the glass-ceramic and enamel. These facts, along with the high hardness, explain the high enamel and antagonist material wear associated with IPS e.max CAD. The SEM images reported by Wang et $\mathrm{al}^{4}$ of the worn enamel surface against lithium disilicate reveal an abrasive wear, with rough furrows with enamel granules chipped off, extruded lithium disilicate crystalline grains and fragments. Therefore, some materials may have their surface roughness and coefficient of friction changed during the wear process, explaining the poor relationship between these 2 properties and the wear potential. Metzler et $\mathrm{al}^{13}$ evaluating the wear of enamel provided by feldspathic porcelains commented that the surface of the material is important in the beginning, but after the surface has been changed, the nature of the material determines the wear rates.

The SEM images of the enamel surface worn by the Vita Suprinity and IPS e.max CAD indicate an abrasive wear mechanism, as observed by some authors for IPS e.max CAD. ${ }^{4,10,11}$ The sliding grooves created by the Lava Plus differ slightly from the observations of the study by Stawarczyk et $\mathrm{al}^{5}$ in which cracks were observed on the enamel surface worn by polished monolithic zirconia. The Vita Enamic produced small cracks and Lava Ultimate an essentially smooth surface, which is in agreement with the images reported by Mormann et al. ${ }^{6}$ The SEM images of the materials show that the Lava Ultimate and Lava Plus did not damage the surface of the materials, despite the high wear rate produced by this last material. In contrast, the Vita Suprinity and IPS e.max CAD caused more damage to the materials. Some pits were observed on the surface of the Lava Ultimate and Vita Enamic when against Vita Suprinity. Pits were also present on the surface of the Vita Enamic and Vita Suprinity as a result of the sliding against the IPS e.max CAD with supposed fragments of Vita Suprinity on the surface of this last material, suggesting an abrasive wear mechanism. 
A limitation of this study was that the enamel was not used as abrader (not possible with the methodology used); therefore, qualitative and quantitative information about its potential to wear itself and the evaluated antagonist materials is lacking.

\section{CONCLUSIONS}

Based on the findings of this in vitro study, the following conclusions were drawn:

1. The nanofilled composite resin and polymerinfiltrated ceramic were the most antagonistfriendly materials when sliding against enamel and any other material.

2. Lithium disilicate, zirconia-reinforced lithium silicate, and zirconia caused high wear rates on the enamel and materials, with the difference that zirconia did not damage the surface of the materials, except for the enamel.

3. Hardness should be considered in the selection of materials, especially in patients with bruxism.

\section{REFERENCES}

1. Quinn GD, Hoffman K, Quinn JB. Strength and fracture origins of a feld spathic porcelain. Dent Mater 2012;28:502-11.

2. Sannino G, Germano F, Arcuri L, Bigelli E, Arcuri C, Barlattani A. CEREC CAD/CAM chairside system. Oral Implantol (Rome) 2015;7:57-70.

3. Rosentritt M, Preis V, Behr M, Hahnel S, Handel G, Kolbeck C. Two-body wear of dental porcelain and substructure oxide ceramics. Clin Oral Invest 2012;16:935-43.

4. Wang L, Liu Y, Si W, Feng H, Tao Y, Ma Z. Friction and wear behaviors of dental ceramics against natural tooth enamel. J Eur Ceram Soc 2012;32 2599-606.

5. Stawarczyk B, Özcan M, Schmutz F, Trottmann A, Roos M, Hämmerle CH Two-body wear of monolithic, veneered and glazed zirconia and their corresponding enamel antagonists. Acta Odontol Scand 2013;71:102-12.

6. Mörmann WH, Stawarczyk B, Ender A, Sener B, Attin T, Mehl A. Wear characteristics of current aesthetic dental restorative CAD/CAM materials: two-body wear, gloss retention, roughness and Martens hardness. J Mech Behav Biomed Mater 2013;20:113-25.

7. Janyavula S, Lawson N, Cakir D, Beck P, Ramp LC, Burgess JO. The wear of polished and glazed zirconia against enamel. J Prosthet Dent 2013:109.22-9.

8. Stawarczyk B, Frevert K, Ender A, Roos M, Sener B, Wimmer T. Comparison of four monolithic zirconia materials with conventional ones: Contrast ratio, grain size, four-point flexural strength and two-body wear. J Mech Behav Biomed Mater 2016;59:128-38.

9. Figueiredo-Pina CG, Patas N, Canhoto J, Cláudio R, Olhero SM, Serro AP, et al. Tribological behaviour of unveneered and veneered lithium disilicate dental material. J Mech Behav Biomed Mater 2016;53:226-38.

10. Lawson NC, Bansal R, Burgess JO. Wear, strength, modulus and hardness of CAD/CAM restorative materials. Dent Mater 2016;32:e275-83.
11. Culhaoglu AK, Park J. A comparison of the wear resistance and hardness of two different indirect composite resins with a ceramic material, opposed to human enamel. European J Gen Dent 2013;2:274-80.

12. Zhi L, Bortolotto T, Krejci I. Comparative in vitro wear resistance of CAD/ CAM composite resin and ceramic materials. J Prosthet Dent 2016;115: 199-202.

13. Metzler KT, Woody RD, Miller AW 3rd, Miller BH. In vitro investigation of the wear of human enamel by dental porcelain. J Prosthet Dent 1999;81: 356-64.

14. Freddo RA, Kapczinski MP, Kinast EJ, de Souza Junior OB, Rivaldo EG, da Fontoura Frasca LC. Wear potential of dental ceramics and its relationship with microhardness and coefficient of friction. J Prosthodont 2016;25: 557-62.

15. Seghi RR, Rosenstiel SF, Bauer P. Abrasion of human enamel by different dental ceramics in vitro. J Dent Res 1991;70:221-5.

16. Oh WS, Delong R, Anusavice KJ. Factors affecting enamel and ceramic wear: a literature review. J Prosthet Dent 2002;87:451-9.

17. Belli R, Wendler M, de Ligny D, Cicconi MR, Petschelt A, Peterlik H, et al. Chairside CAD/CAM materials. Part 1: Measurement of elastic constants and microstructural characterization. Dent Mater 2017;33:84-98.

18. Chun KJ, Choi HH, Lee JY. Comparison of mechanical property and role between enamel and dentin in the human teeth. J Dent Biomech 2014;5: 1758736014520809

19. Galvão Ribeiro BR, Galvão Rabelo Caldas MR, Almeida AA Jr, Fonseca RG, Adabo GL. Effect of surface treatments on repair with composite resin of a partially monoclinic phase transformed yttrium-stabilized tetragonal zirconia. J Prosthet Dent 2018;119:286-91.

20. Kohorst P, Borchers L, Strempel J, Stiesch M, Hassel T, Bach FW, et al. Low temperature degradation of different zirconia ceramics for dental applications. Acta Biomater 2012;8:1213-20.

21. Cattani-Lorente M, Scherrer SS, Ammann P, Jobin M, Wiskott A. Low temperature degradation of a Y-TZP dental ceramic. Acta Biomater 2011;7: 858-65.

22. He LH, Fujisawa N, Swain MV. Elastic modulus and stress-strain response of human enamel by nano-indentation. Biomaterials 2006;27:4388-98.

23. Chan YL, Ngan AHW, King NM. Nano-scale structure and mechanical properties of the human dentine-enamel junction. J Mech Behav Biomed Mater 2011:4:785-95.

24. Awada A, Nathanson D. Mechanical properties of resin-ceramic CAD/CAM restorative materials. J Prosthet Dent 2015;114:587-93.

25. Ghazal M, Kern M. The influence of antagonistic surface roughness on the wear of human enamel and nanofilled composite resin artificial teeth. J Prosthet Dent 2009;101:342-9.

26. Lambrechts P, Braem M, Vuylsteke-Wauters M, Vanherle G. Quantitative in vivo wear of human enamel. J Dent Res 1989;68:1752-4.

27. ASTM Standard G133-05. Standard test method for linearly reciprocating ball-on-flat sliding wear. West Conshohocken: ASTM International; 2010.

28. de Gee AJ, Pallav P. Occlusal wear simulation with the ACTA wear machine. J Dent 1994;22:S21-7.

29. Benetti AR, Larsen L, Dowling AH, Fleming GJ. Assessment of wear facets produced by the ACTA wear machine. J Dent 2016:45:19-25.

\section{Corresponding author:}

Dr Renata Garcia Fonseca

Department of Dental Materials and Prosthodontics

School of Dentistry, São Paulo State University (UNESP)

Rua Humaitá, 1680, Araraquara, São Paulo 14801-903

BRAZIL

Email: renata@foar.unesp.br

Copyright () 2018 by the Editorial Council for The Journal of Prosthetic Dentistry. 